\title{
A numerical analysis of compressive residual stresses in cold gas dynamic spray (CGDS) deposition method
}

\author{
Sunday Temitope Oyinbo ${ }^{\mathrm{a}}$ and Tien-Chien Jen ${ }^{\mathrm{a}^{*}}$
}

\begin{tabular}{|c|c|}
\hline ARTICLEINFO & ABSTRACT \\
\hline $\begin{array}{l}\text { Article history: } \\
\text { Received } 20 \text { May } 2020 \\
\text { Accepted } 30 \text { July } 2020 \\
\text { Available online } \\
30 \text { July } 2020 \\
\text { Keywords: } \\
\text { CGDS } \\
\text { Contact Analysis } \\
\text { Residual Stress } \\
\text { Impact Velocity }\end{array}$ & $\begin{array}{l}\text { This study presents a finite element approach of a numerical model to investigate the profile of the } \\
\text { deformed sprayed particles and the compressive residual stresses analysis at the interfacial zone of } \\
\text { particle and substrate impact using cold gas dynamic spray (CGDS). The Lagrangian approach was } \\
\text { used to analyze, in details, the material deformation behavior during impact, contact problems of } \\
\text { single-particle impact process and the outputs of equivalent plastic strain and temperature to achieve } \\
\text { a qualitative understanding of cold gas dynamic spray contact process of cold sprayed particle on the } \\
\text { substrate. The evolution of residual compressive stresses during impact was also analyzed for multiple- } \\
\text { particles impact process using the Lagrangian approach. It can be observed that the compressive } \\
\text { residual stresses increase by increasing the preheating temperature and particle initial impact velocity. }\end{array}$ \\
\hline
\end{tabular}

\section{Introduction}

The cold gas dynamic spray (CGDS) is a deposition process of materials with the aid of accelerating relatively small particles varying from $10 \mu \mathrm{m}$ to $50 \mu \mathrm{m}$ size with the help of a propellant gas flow at supersonic velocity to accelerate the particles to very high speed (greater than $500 \mathrm{~m} / \mathrm{s}$ ) typically. Subsequently, these particles impact the substrate to create the film of desire. This impact allows bonding to take place between the particles and substrate as soon as deformation happens (Grujicic et al., 2003; Lu et al., 2019; Oyinbo \& Jen, 2019; Raoelison et al., 2017; Richer et al., 2008; Seraj et al., 2019; Zhang et al., 2008). However, the mechanism for bonding is technically complex because it is difficult to explain this bonding process. A possible evidence in this regard is the short impact process during the experiment. Notwithstanding, the numerical approach seems one of the best options or solutions for explaining this bonding mechanism. But before this identified solution or option, there are other approaches which have been used such as the analytical and experimental approach of fine structural characterization. Past computational simulations (Bae et al., 2008, 2009; Guetta et al., 2009; Assadi et al. 2003; King et al., 2010; Abreeza Manap et al., 2012; Oyinbo \& Jen, 2020; Takana et al., 2008) have shown that meshbased finite element analysis (FEA) using Lagrangian codes and finite difference analysis (FDA) codes to investigate the cold spray bonding mechanism have associated limitations of excessive mesh distortion and difficulty in tracing moving and free interfaces respectively, and this approach is unsuitable to predict

* Corresponding author.

E-mail addresses: tien@uj.ac.za (T.C. Jen) 
accurately the critical velocity (Yin et al., 2011). They made the assessment difficult in a number of ways until recently smoothed particle hydrodynamics (SPH) method proved vital or fairly attractive in solving solid mechanic problems related to the high-velocity impact of bonding identified above (Gnanasekaran et al., 2019; Manap et al., 2011a,b, 2012; Zhou et al., 2007).

Cold spray deposition process has been extensively studied by LS-DYNA and ABAQUS, (the explicit finite element commercial packages) to study the deposition and bonding mechanism during the particle and substrate impact. Also these codes can be used for predict the threshold velocity, that is the critical velocity above which there is adherence between the particles and the base material. Mostly in the literature (e.g. Bae et al., 2008, 2009; Grujicic et al., 2004b; Assadiet al. 2003; Hassani-Gangaraj et al., 2018; Kim et al., 2010; King et al., 2010; Li \& Gao, 2009; Yin et al., 2013), the Lagrangian numerical algorithm is the focus of many researchers. 3D and axisymmetric models for particle and substrate impact was first used by Assadi et al. (2003), to establish the impact phenomenon by using ABAQUS/Explicit version 6.2-1. Yin et al. (2013), Li et al. (2006), and Grujicic et al. (2004b) also investigated the behavior of particles and substrate during impact with the application of Lagrangian analysis model. Li et al. (2006) were among the first researchers that incorporated material damage mechanisms in the model as well as Lagrangian adaptive mesh domains (Lagrangian-Eulerian method) to control the excessive element distortion and mesh size control respectively.

Therefore, this study presented a finite element approach of a numerical model to investigate the profile of the deformed sprayed particles and the residual stresses analysis at the interfacial zone of particle and substrate impact during CGDS by using Lagrangian approach of ABAQUS explicit software.

\section{Material model description}

The explicit finite element analysis program, ABAQUS / Explicit version 6.14-1 was used to study the profile of the deformed sprayed particles and the compressive residual stresses analysis for solid particle impact on ductile material such as Copper $(\mathrm{Cu})$, and Aluminum (Al) during CGDS using Lagrangian approach. This study was carried out using single and multiple particle impacts to examine the effect of initial velocity and preheating temperature of the impacting particles on the residual stress. Fig. 1(a)-(b) shows the basic dimensions used for the assembled particle/ substrate in the Lagrangian domain. The particle morphology used for the numerical model is spherical due to the SEM observation in Fig. 1(c). The direction of the deformed particle (radial path) was chosen for proper observation of the equivalent plastic strain (PEEQ) and temperature (TEMP) evolution. The initial impact velocity of 500 $\mathrm{m} / \mathrm{s}$ used for this simulation of $\mathrm{Cu} / \mathrm{Al}$ (particle/substrate) is below its critical velocity. Note that $507 \mathrm{~m} / \mathrm{s}$ is the approximated critical velocity for $\mathrm{Cu} / \mathrm{Al}$ (Grujicic et al., 2004b; Oyinbo \& Jen, 2020; Xie et al., 2015 ) by using shear localization analysis. In the numerical model, the impacting particles were modelled as deformable spherical 3D objects. The linear elasticity model was developed on the Mie-Grüneisen State Equation (EOS). The Mie-Grüneisen formulation was adopted as suggested by ABAQUS analysis user's manual for the material response characterization during the experimental testing condition (Abaqus Analysis User's Manual, 2014). As shown in Eqs. (1)-(3), the pressure ( $p$ ) and the internal energy $\left(E_{m}\right)$ can be calculated simultaneously using the coupled equations (i.e. the equation of state and the energy equation) at each material point.

$$
p=p_{H}\left(1-\frac{\Gamma_{0} \eta}{2}\right)+\Gamma_{0} \rho_{0} E_{m}
$$

where $p_{H}, \Gamma_{0}$, and $\rho_{0}$ are the Hugoniot pressure, the material constant named Gruneisen's gamma, and initial density respectively. Thus, nominal compressive volumetric strain is: $\eta=1-\rho / \rho_{0}$. Linear equation of state can always be written in the below form:

$$
p=f+g E_{m},
$$


where $f(\rho)$ and $g(\rho)$ are functions of density only and depend on the particular equation of state model. The linear Hugoniot form is written as (Abaqus Analysis User's Manual, 2014):

$$
P=\frac{\rho_{0} c_{0}^{2} \eta}{(1-s \eta)^{2}}\left(1-\frac{\Gamma_{0} \eta}{2}\right)+\Gamma_{0} \rho_{0} E_{m}
$$

where $\rho, \rho_{0}, S$ and $c_{0}$ are the current density, initial density, linear Hugoniot slope coefficient and sound bulk speed respectively. The Johnson-Cook plasticity model offers a definition of material movement for both particles and substrate (Li \& Gao, 2009). The flow stress $(\sigma)$ functions as illustrated in Eq. (4) are the strain hardening, strain rate hardening and temperature softening where the working hardening exponent (n) and plastic strain is denoted by $\dot{\varepsilon}$, the dimensionless plastic strain rate is the ratio of $\dot{\varepsilon} / \dot{\varepsilon}_{0}$, $\dot{\varepsilon}_{0}=1.0 \mathrm{~s}^{-1}$ and the substance constants $\mathrm{A}, \mathrm{B}, \mathrm{C}$ and $\mathrm{m}$ are shown in Table $1 . T, T_{m}$ and $T_{0}$ are the measured, melting and reference temperature respectively

$$
\sigma=\left(A+B \varepsilon^{n}\right)\left[1+C \ln \left(1+\frac{\dot{\varepsilon}}{\dot{\varepsilon}_{0}}\right)\right]\left(1-\left[\frac{T-T_{0}}{T_{m}-T_{0}}\right]^{m}\right)
$$

The thermal reaction study is carried out using the thermal conductivity properties and specific heat. Table 1 shows the properties of the materials used for the analysis (Bae et al., 2008; Manap et al., 2011; Yildirim et al., 2011).

Table 1. Material model for the numerical analysis.

\begin{tabular}{llll} 
Properties & & Copper & Aluminum \\
Density $(\sigma)$ & $\mathrm{kgm}^{-3}$ & $8.9 \times 10^{-3}$ & $2.7 \times 10^{-3}$ \\
Shear modulus $(G)$ & $\mathrm{GPa}$ & 44.7 & 44.7 \\
Thermal conductivity $(\lambda)$ & $\mathrm{W} / \mathrm{m} \cdot \mathrm{K}$ & 386.5 & 237.2 \\
Specific heat $(c)$ & $\mathrm{J} / \mathrm{kg} \cdot \mathrm{K}$ & 383 & 898.2 \\
Sound velocity $\left(C_{0}\right)$ & $\mathrm{m} / \mathrm{s}$ & 3940 & 5386 \\
$\mathrm{U}_{\mathrm{s}}$ versus $\mathrm{U}_{\mathrm{p}}(\mathrm{s})$ & & 1.489 & 1.339 \\
Grüneisen coefficient $\left(\Gamma_{0}\right)$ & & 2.02 & 1.97 \\
$\mathrm{~A}$ & $\mathrm{MPa}$ & 90 & 148.4 \\
$\mathrm{~B}$ & $\mathrm{MPa}$ & 292 & 345.5 \\
$\mathrm{n}$ & & 0.310 & 0.183 \\
$\mathrm{C}$ & & 0.0250 & 0.001 \\
$\mathrm{~m}$ & & 1.090 & 0.895 \\
$\mathrm{~T}_{\mathrm{m}}$ & $K$ & 1356 & 916 \\
$\mathrm{~T}_{0}$ & $K$ & 298 & 293 \\
\hline
\end{tabular}

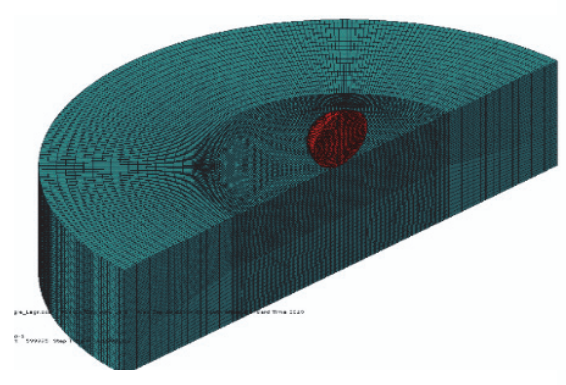

(a)

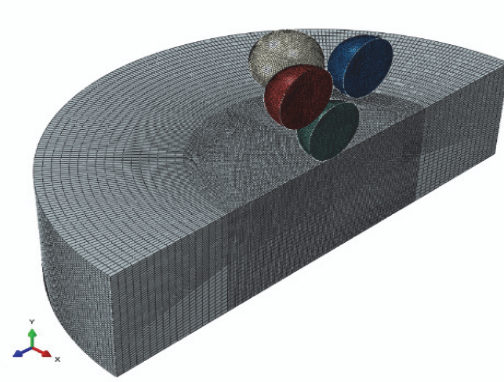

(b)

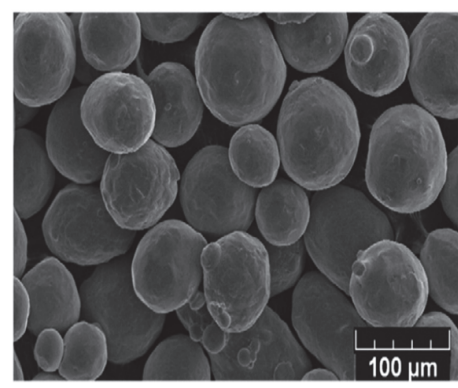

(c)

Fig. 1. Diagram illustrating (a) 3D Lagrangian single particle model (b) 3D Lagrangian multiple particles model (c) Cu particles SEM morphology 


\section{Results and Discussion}

\subsection{Deformation behavior of a single-Particle Impact Process using the Lagrangian approach}

The experimental observation (King et al., 2010) of $\mathrm{Cu} / \mathrm{Al}$ deformation after impact and the results of three dimensional-numerical simulations using CEL approach are shown in Fig. 2. Fig. 3 shows the mean stress distributions at the time interval of $60 \mathrm{~ns}$ of $\mathrm{Cu} / \mathrm{Al}$ impact at $500 \mathrm{~m} / \mathrm{s}$. This is also called PRESSURE in ABAQUS/Explicit. The compressive stresses are positive, and the tensile stresses are negative (colored black). Around $10 \mathrm{~ns}$, near to the contact area, the high-speed impact has caused great compressive stress. Over time, the compressive and the tensile stress region expands and shrinks respectively. At the symmetry axis underneath the substrate surface, tensile stresses start building up after 10 ns. Particle rebound occurs before the tensile stress region growth reaches the surface of the substrate. After the impact, the maximum plastic strain was found at the contact edge and small region of tensile stress occurs locally at these regions too. But a large compressive stress region is observed from the contact center downward the substrate as indicated by Fig. 3(f). The material fatigue resistance can be greatly improved by this compressive residual stress, and the detail will be discussed in section 3.2 .

At various times, the evolutions of the strain rate are shown in Fig. 4 for both the substrate and the particle in the radial direction over the contact zone. It is clear at $5 \mathrm{~ns}$ that the strain rates attain the highest value of $0.23 \times 10^{9} \mathrm{~s}^{-1}$ in the particle/substrate. Then, there is a decrease of strain rates at $15 \mathrm{~ns}$ below $1 \times 10^{8} \mathrm{~s}^{-1}$, and attain the minimum value at $30 \mathrm{~ns}$. At $30 \mathrm{~ns}$ it is important to note that the value of strain rates is in the range of $10^{4} s^{-1}$, but not zero. The substrate strain rate is higher in all respect than that of the particle. Although the higher value of these strain rates is recorded, their concentration is in a very local area instead of the whole contact area.

Fig. 5 indicates the development of the PEEQ and TEMP of the $\mathrm{Cu} / \mathrm{Al}$ interface across the contact zone in the radial direction and at various times. It can be easily seen that both PEEQ and TEMP rise from the middle of a contact area with the gradual development of the deformation along the horizontal direction. In the contact zone, the $\mathrm{Cu}$ material becomes softer and deforms plastically than the material of the $\mathrm{Cu}$ substrate in the other region, and therefore the particles travel uniformly with the substrate surface
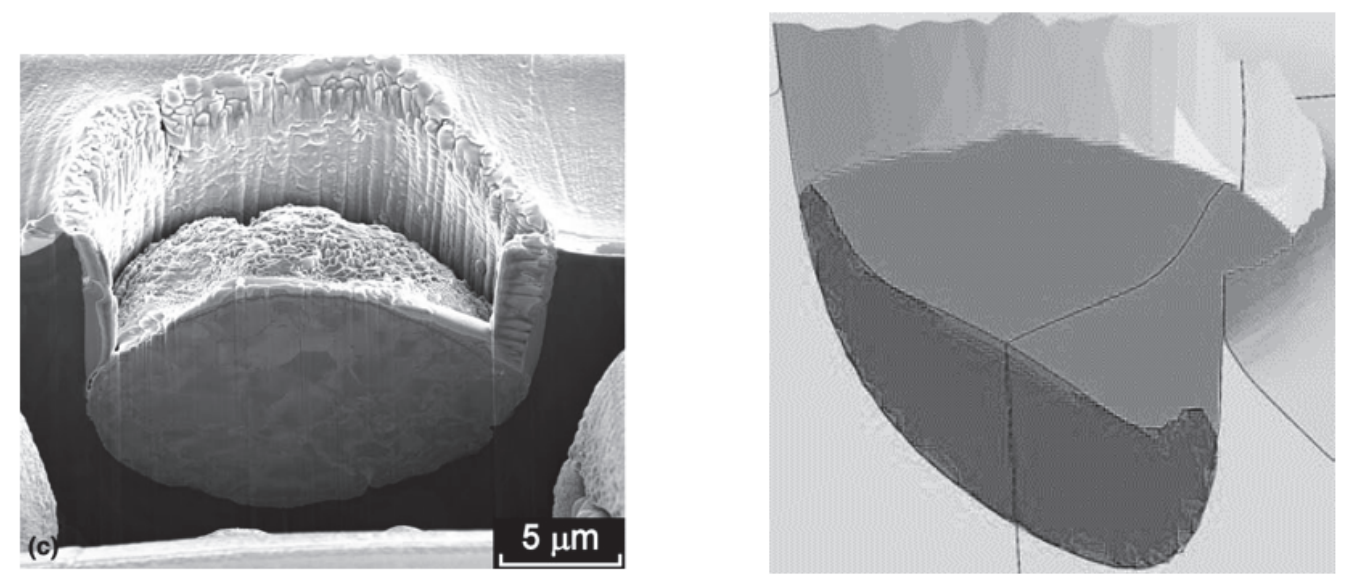

Fig. 2. The schematic illustration of $\mathrm{Cu} / \mathrm{Al}$ deformation (a) SEM observation (King et al., 2010) (b) 3D simulation calculation. 


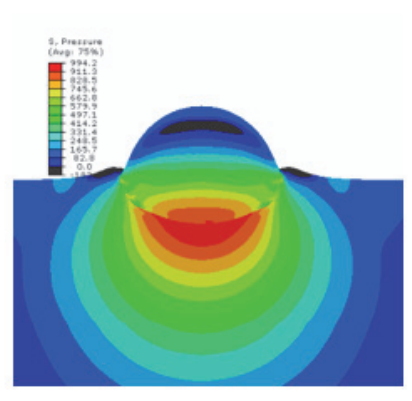

(a)

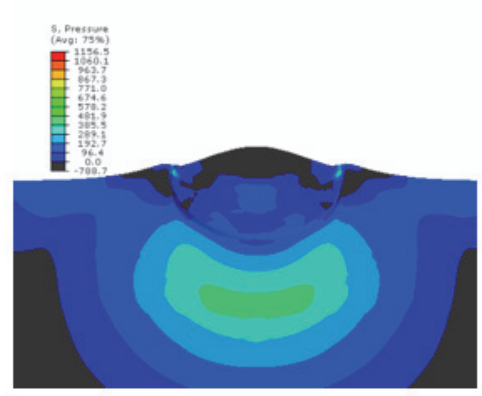

(d)

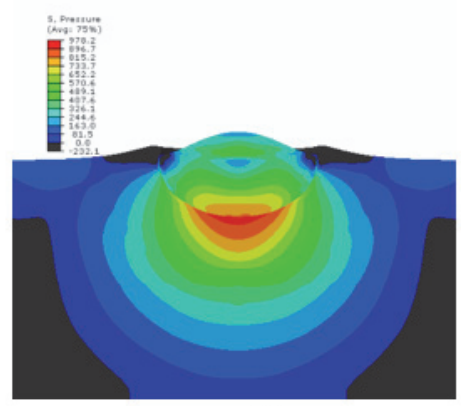

(b)

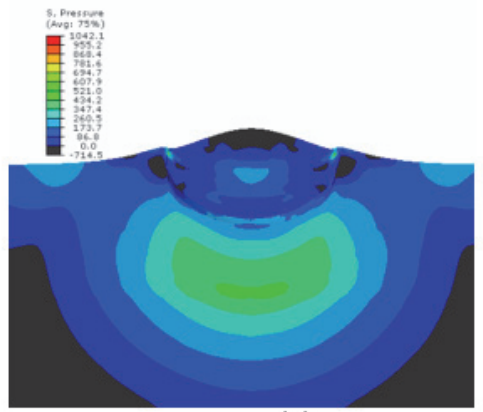

(e)

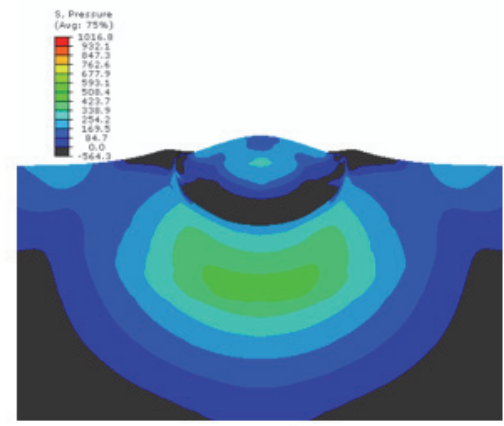

(c)

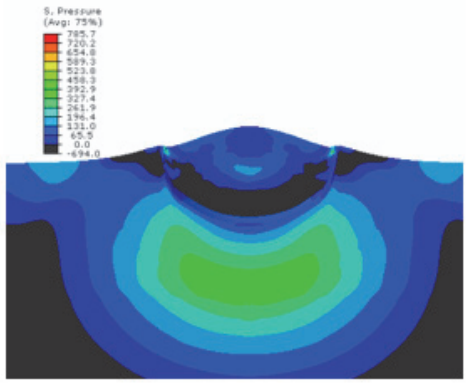

(f)

Fig. 3. The mean stress evolution at (a) $10 \mathrm{~ns}$ (b) $20 \mathrm{~ns}$ (c) $30 \mathrm{~ns}$ (d) $40 \mathrm{~ns}$ (e) $50 \mathrm{~ns}$ (f) $60 \mathrm{~ns}$ at $500 \mathrm{~ms}^{-1}$ $\mathrm{Cu} / \mathrm{Cu}$ impact

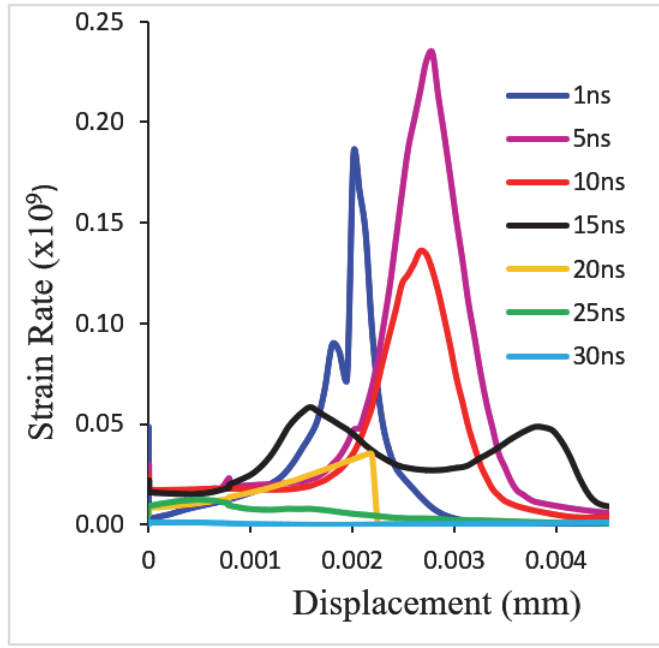

(a)

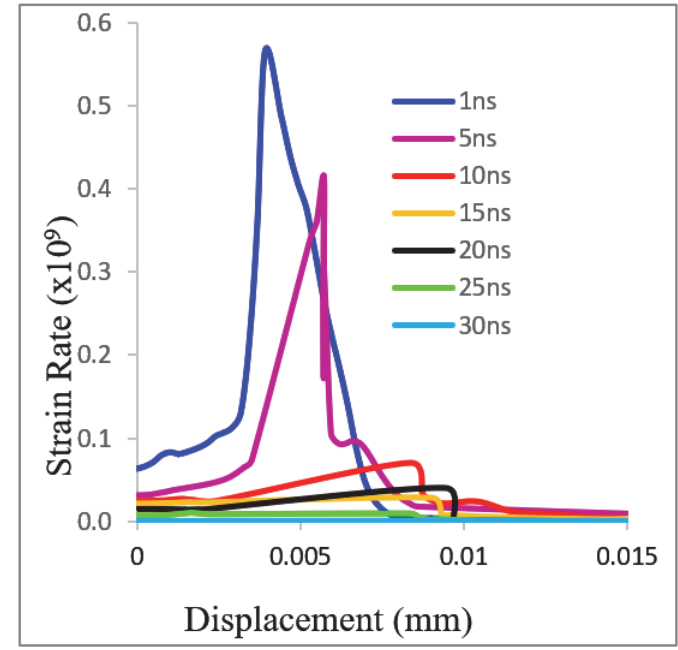

(b)

Fig. 4. Strain rate evolution at $500 \mathrm{~m} / \mathrm{s} \mathrm{Cu} / \mathrm{Al}$ impact at different impacting time histories along the radial path for (a) particle (b) substrate 


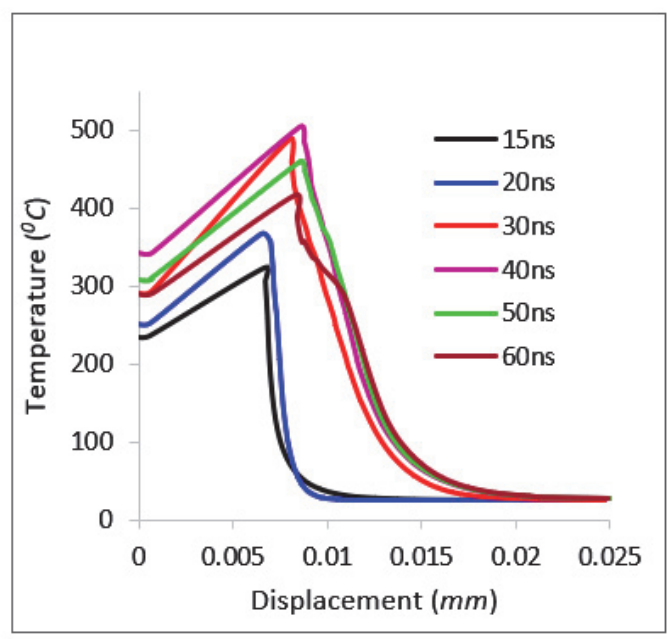

(a)

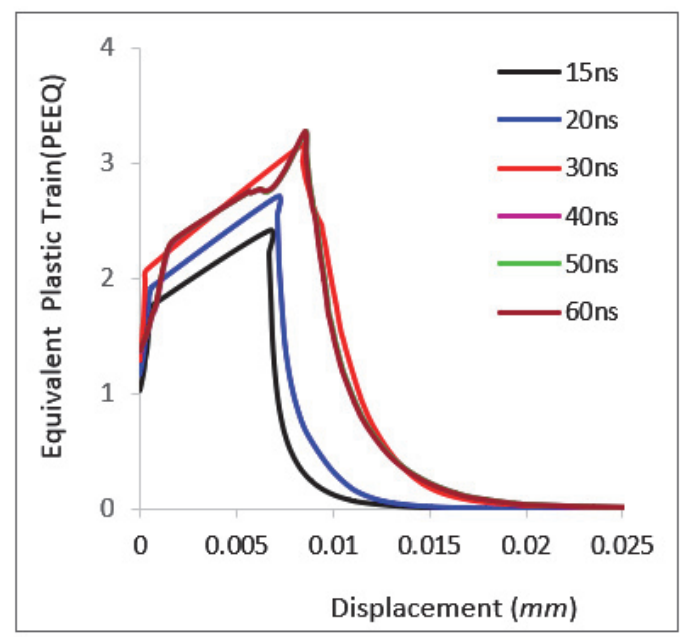

(b)

Fig. 5. The distribution of (a) Temperature and (b) PEEQ with initial impact velocity of $500 \mathrm{~m} / \mathrm{s}$ along the radial direction of the $\mathrm{Cu} / \mathrm{Al}$ contact surface

\subsection{Residual stress in multiple-Particle Impact Process using the Lagrangian approach}

The quality of bonding can be termed coating integrity between the particles and the substrate within the coating (Luzin et al., 2011; Xie et al., 2015). The presence of residual stresses within the coating influences the integrity of the coating. A numerical analysis is the best choice of analyzing the cold gas dynamic spray complexity in order to capture the details of stress accumulation mechanics. There are three stresses in cold gas dynamic sprayed coating namely; peening, thermal mismatch and quench stresses. Due to the limitation of calculation time, it is difficult to determine the thermal mismatch stress because cooling of the particle/substrate system in the simulation to room temperature is impossible. Therefore, the only stress considered in this study is peening stress and quenching stress. The combination of their effect is called evolving stress, which is the stress experienced when particles are deposited on to the substrate (Suhonen et al., 2013). Fig. 6 shows the distributions of mean stress (through-thickness stress) obtained from the simulation of four-particle impacts using the Lagrangian approach for different process material combinations ( $\mathrm{Al} / \mathrm{Al}, \mathrm{Al} / \mathrm{Cu}, \mathrm{Cu} / \mathrm{Cu} /$ and $\mathrm{Cu} / \mathrm{Al})$ at $500 \mathrm{~m} / \mathrm{s}(\mathrm{Xie}$ et al., 2015). The selection of data is along the y-axis (axis of symmetry), from the point of the particle impact to the lower part of the substrate. From Fig. 6 the compressive stresses are denoted by the positive stresses while the tensile stresses are represented by the negative stresses.

The deposited particles induce distinguishing compressive stress beneath the substrate surface by well-build plastic deformation of the impacted particles as a result of the peening stress. $\mathrm{Cu} / \mathrm{Al} \mathrm{impact}$ experienced the maximum value of compressive stress which is $1535.1 \mathrm{MPa}$ among the four cases of impact (Fig. 7). The highest compressive stress generated by $\mathrm{Cu}$ particles impact can be observed at a depth closer to the surface of the substrate while the highest compressive stress generated is located at a distance close to $15 \mu \mathrm{m}$ in the case of Al particles impact (Fig. 7). Along the y-axis, the compressive residual stress magnitude starts reducing after reaching its peak value. As the compressive stress approaching zero, there is a little observation of the compensatory tensile stress.

Fig 7 shows the plastic deformation of the four cases of particle/substrate impact at $500 \mathrm{~m} / \mathrm{s}$. As illustrated in Fig. 7(c)-(d), all the particles of $\mathrm{Cu}$ deform plastically into a shape that is lens-like, while, on the contrary, the Al particles at the top layer experienced partial deformation (Fig. 7(a)-(b)) with respect to the deformation of the first particle layer (this is because the impact velocity, $500 \mathrm{~m} / \mathrm{s}$ is far below the Al critical velocity of $766 \mathrm{~m} / \mathrm{s}$ (Grujicic et al., 2004b), and give rise to the distribution of the 
tensile stresses among the particles of $\mathrm{Al}$. $\mathrm{Cu}$ particles produce more than two times the compressive residual stress at impact than what $\mathrm{Al}$ particles produced in their respective substrate. The compressive residual stress that is evidently higher in values in $\mathrm{Cu} / \mathrm{Al}$ and $\mathrm{Cu} / \mathrm{Cu}$ impact cases is an indication that there is a significant amount of plastic deformation on impact because the initial kinetic energy is higher for $\mathrm{Cu}$ particles.

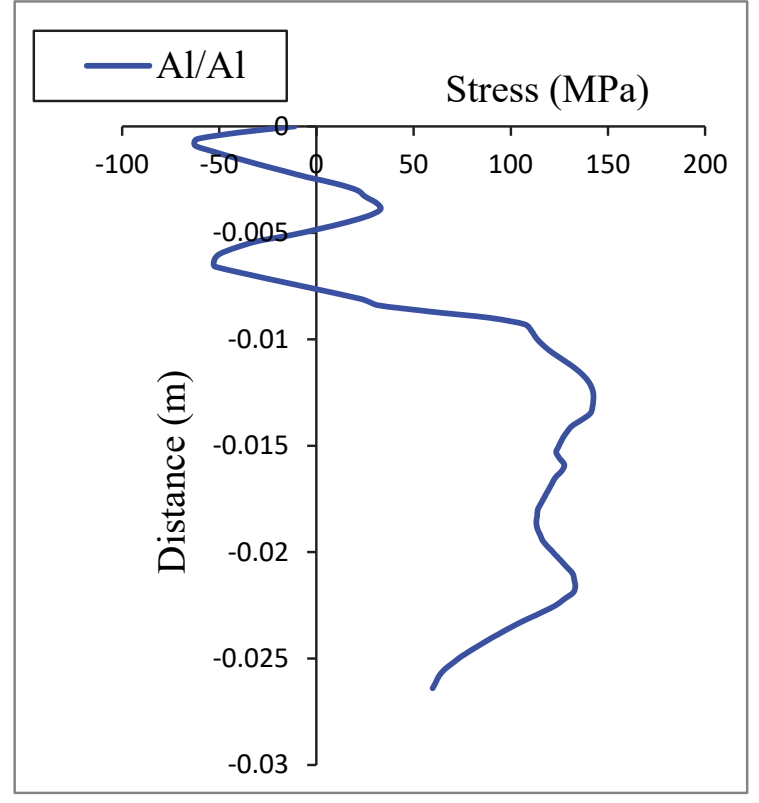

(a)

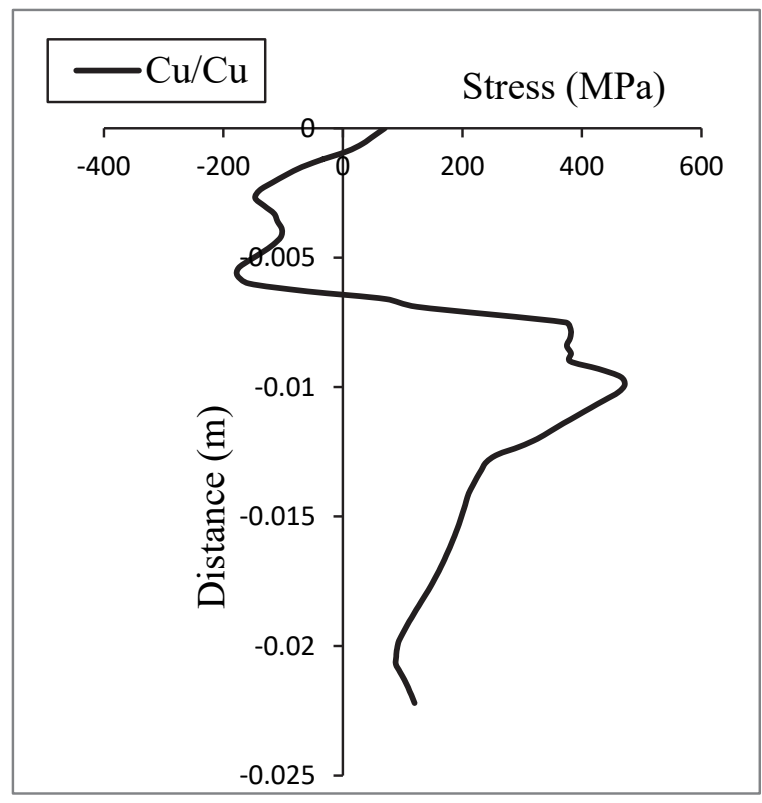

(c)

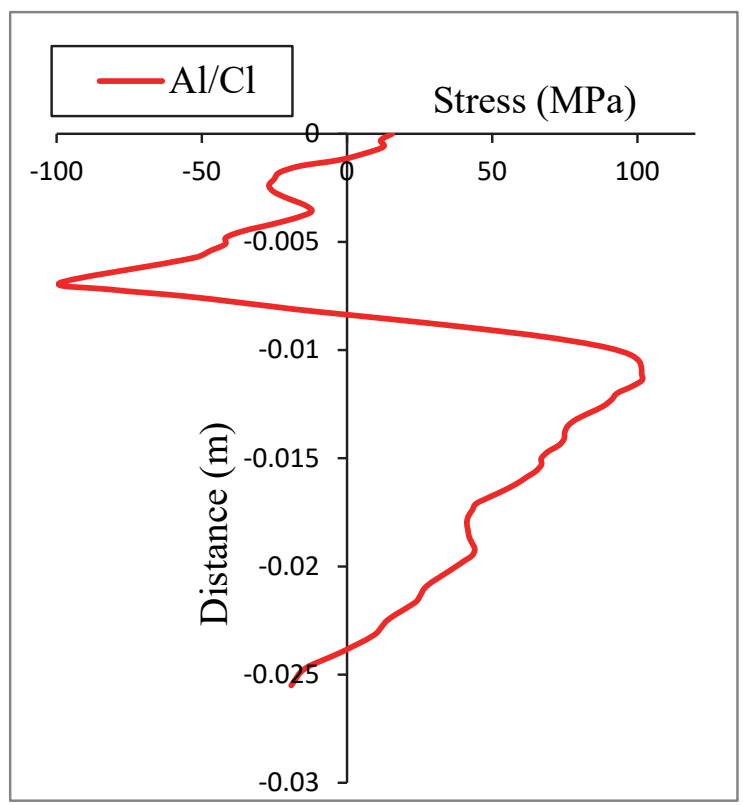

(b)

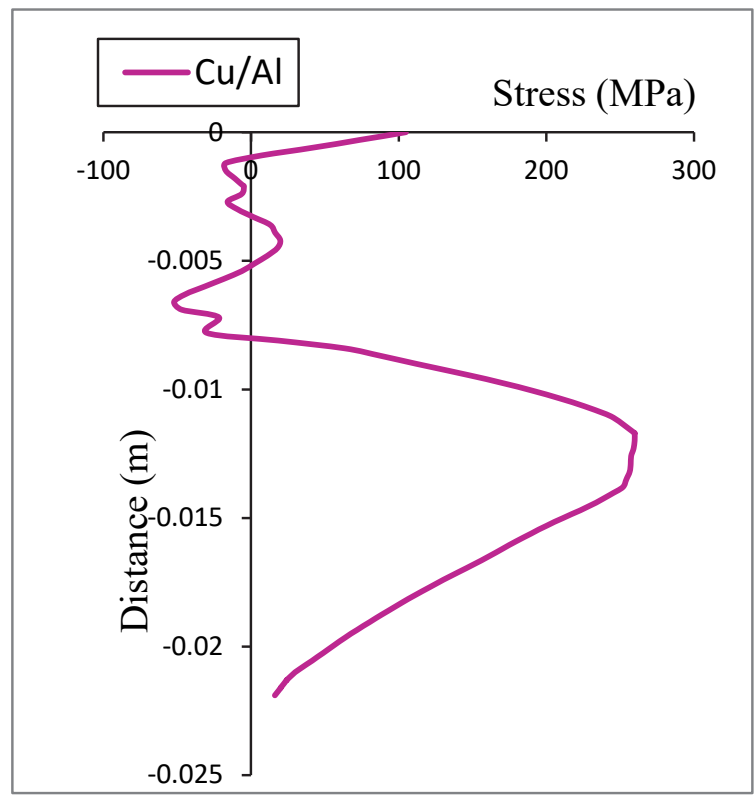

(d)

Fig. 6. The distributions of through-thickness mean stress for (a) Aluminium/Aluminium (b) Aluminium/Copper (c) Copper/Copper and (d) Copper/Aluminium

The residual stress distribution is significantly influenced by the preheating temperature and impact velocity. In Fig. 8, the $\mathrm{Cu} / \mathrm{Cu}$ impact simulation results with varying process conditions of the distribution 
of mean stress are shown. As shown in Fig. 8(a)-(b), there is an observation of a $60.0 \%$ increase in the maximum value of residual stress with respect to an increase in the impact velocity by $200 \mathrm{~m} / \mathrm{s}$. Moreover, there is an $8.5 \%$ increase in the maximum value of compressive residual stress with respect to an increase in the preheating temperature by $200^{\circ} \mathrm{C}$ (Fig. 8(c)-(d)). A larger amount of material plasticity is obtained with higher kinetic energy as a result of an increase in the impact velocity and preheating temperature thereby give rise to a higher compressive residual stress. At higher preheating temperature and higher particle impact velocity, there is the significance of this relative displacement thereby increases the tensile stress between the particle/ substrate interface. At the interfacial zone, compressive stress decreases as the tensile stress increases between the substrate and particle.

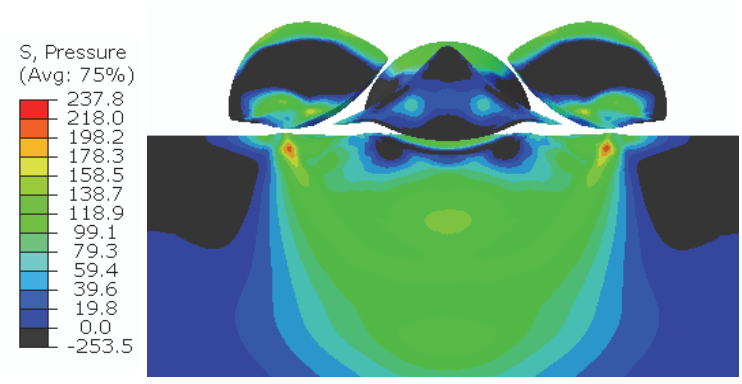

(a)

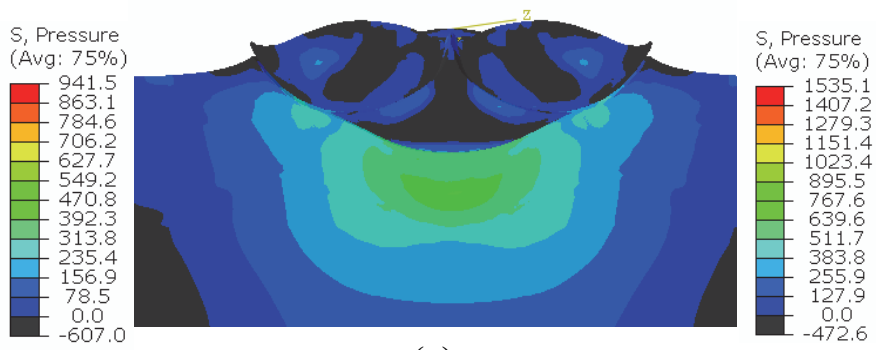

(c)

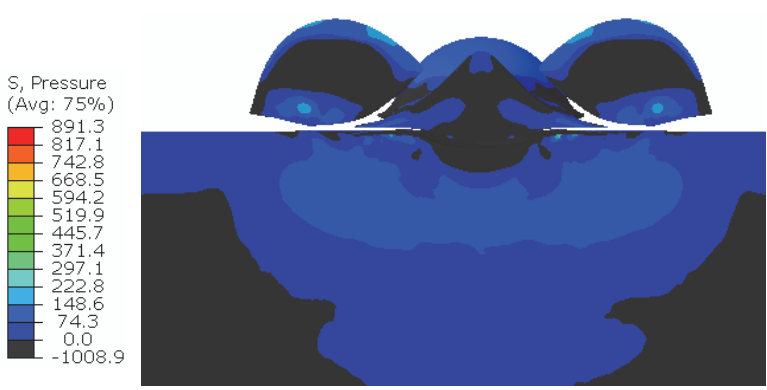

(b)

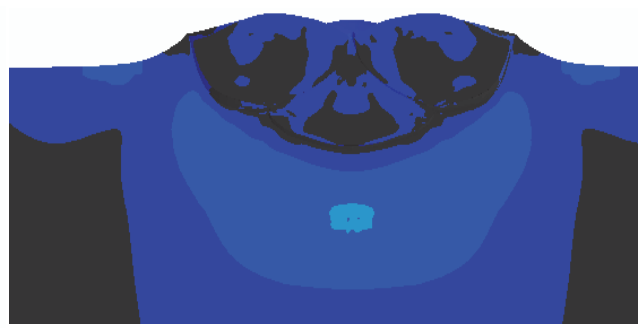

(d)

Fig. 7. The distributions of compressive and tensile residual stresses for (a) $\mathrm{Al} / \mathrm{Al}$ (b) $\mathrm{Al} / \mathrm{Cu}$ (c) $\mathrm{Cu} / \mathrm{Cu}$ and (d) $\mathrm{Cu} / \mathrm{Al}$

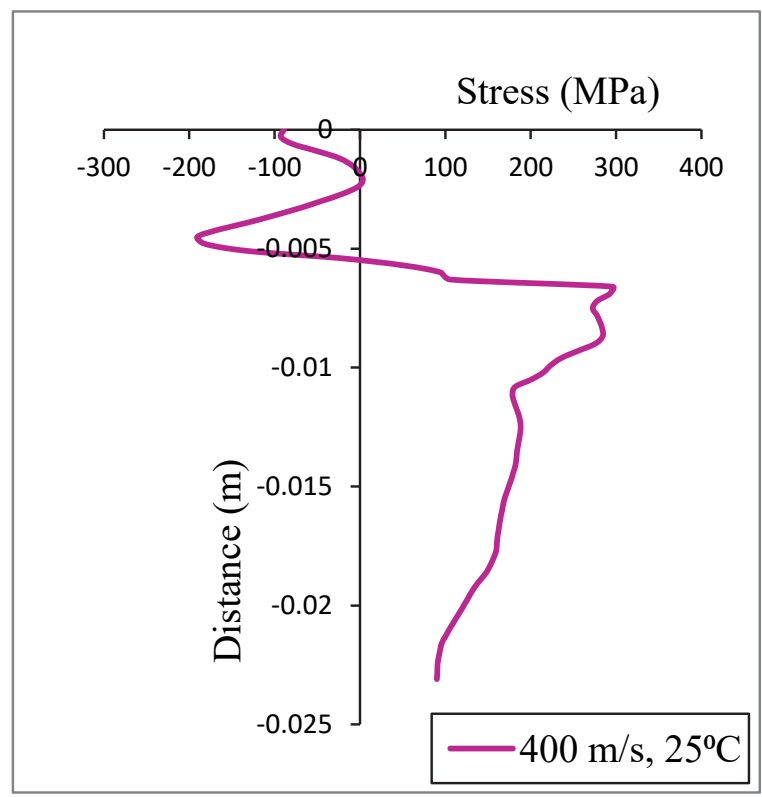

(a)

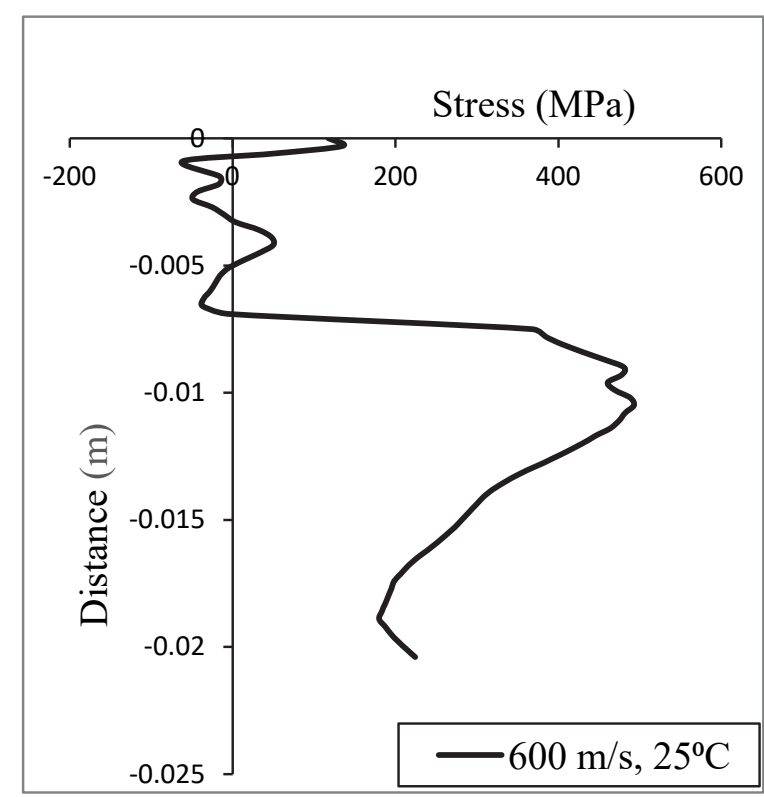

(b) 


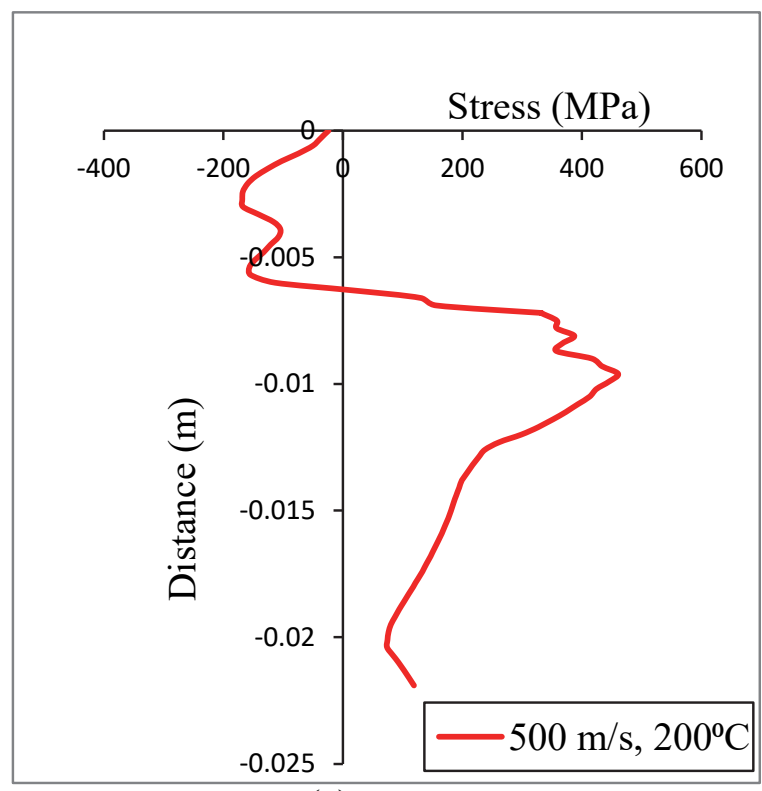

(c)

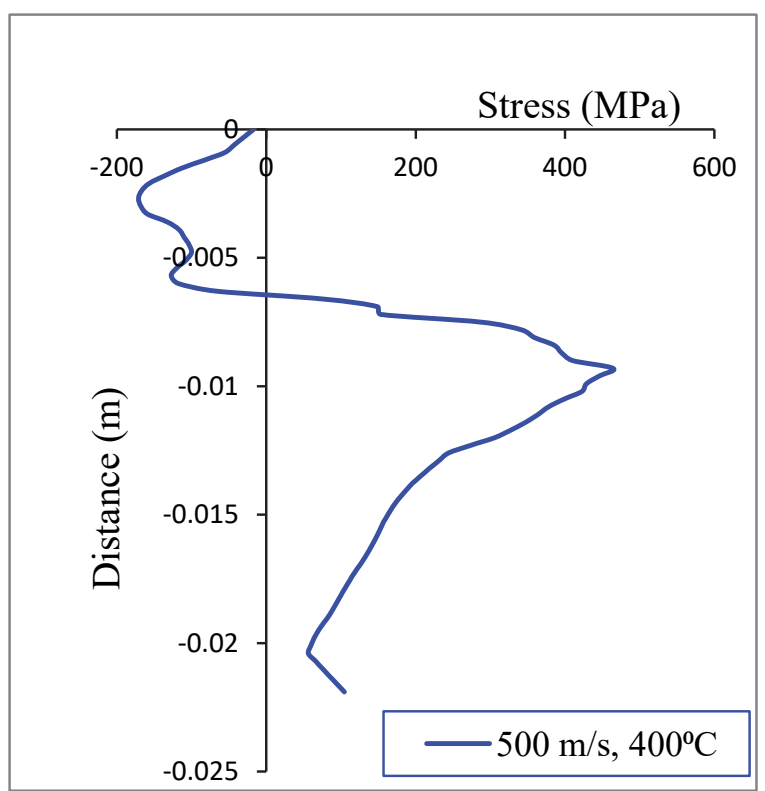

(d)

Fig. 8. The distributions of through-thickness mean stress for $\mathrm{Cu} / \mathrm{Cu}$ (a) $400 \mathrm{~m} / \mathrm{s}, 25^{\circ} \mathrm{C}$ (b) $500 \mathrm{~m} / \mathrm{s}, 25^{\circ} \mathrm{C}$ (c) $600 \mathrm{~m} / \mathrm{s}, 25^{\circ} \mathrm{C}$ (d) $500 \mathrm{~m} / \mathrm{s}, 200^{\circ} \mathrm{C}$ (e) $500 \mathrm{~m} / \mathrm{s}, 400^{\circ} \mathrm{C}$ (f) $500 \mathrm{~m} / \mathrm{s}, 600^{\circ} \mathrm{C}$

\section{Conclusion}

The following conclusions based on the simulation of deformation process using Lagrangian approach of Abaqus/Explicit software were drawn:

- The computational efficiency of the Lagrangian approach and its ability to simulate complex material model makes it one of the most used numerical methods. But the severe distortion of the mesh structure in the deformed area can results in non-convergence and inaccuracy of the calculated result due to numerical backslide effects.

- The evolution of compressive stress, tensile stress, strain rate, PEEQ, and TEMP of a single-particle impact process are discussed in detail using the Lagrangian approach in order to accomplish a qualitative understanding of cold gas dynamic spray contact process of cold sprayed particle on the substrate. In general, it was noticed in the materials a region of compressive stress at particle and substrate interfacial zone $10 \mathrm{~ns}$ after the first impact, where large plastic strains were induced. Plastic deformation region of high strain rate was seen to be locally located at the particle bottom and at a few distances under the surface of the substrate due to the short contact time $\left(10^{9} s^{-1}\right)$ and about $1 \mathrm{GPa}$, high contact pressure.

- The last section of this study shows the residual stresses in the multiple-particles impact process using the Lagrangian approach. Depending on the type of material combination system for particle and substrate impact, the type and magnitude of the residual stresses may significantly vary. The stress generation mechanism that is differently manifested during cold gas dynamic spray deposition induces compressive residual stress at the interfacial region. This mechanism can be associated not only to the elastic nature of the material but more importantly the material plastic properties. Beneath the substrate contact surface, the compressive residual stress increases with respect to an increase in the preheating temperature and initial impact velocity. 


\section{Acknowledgement}

The authors would like to acknowledge the financial support from the National Research Foundation (NRF) and the University Research Committee (URC) of the University of Johannesburg of South Africa.

\section{Declaration of Competing Interest}

The authors declare that they have no known competing financial interests or personal relationships that could have appeared to influence the work reported in this paper.

\section{References}

Abaqus Analysis User's Manual. (2014). ABAQUS 6.14 HTML Documentation, Dassault Systemes.

Assadi, F.H., Gartner, T., \& Stoltenhoff, H. K. (2003). Bonding mechanism in cold gas spraying. Acta Materialia Inc, 6454(February 2016), 4379-4394. https://doi.org/10.1016/S1359-6454(03)00274-X

Bae, G., Kumar, S., Yoon, S., Kang, K., Na, H., Kim, H. J., \& Lee, C. (2009). Bonding features and associated mechanisms in kinetic sprayed titanium coatings. Acta Materialia, 57(19), 5654-5666. https://doi.org/10.1016/j.actamat.2009.07.061

Bae, G., Xiong, Y., Kumar, S., Kang, K., \& Lee, C. (2008). General aspects of interface bonding in $\begin{array}{lllll}\text { kinetic sprayed } \quad \text { coatings. } & \text { Acta }\end{array}$ https://doi.org/10.1016/j.actamat.2008.06.003

Gnanasekaran, B., Liu, G.-R., Fu, Y., Wang, G., Niu, W., \& Lin, T. (2019). A Smoothed Particle Hydrodynamics (SPH) procedure for simulating cold spray process - A study using particles. Surface and Coatings Technology, 377, 124812. https://doi.org/10.1016/j.surfcoat.2019.07.036

Grujicic, M., Saylor, J. R., Beasley, D. E., DeRosset, W. S., \& Helfritch, D. (2003). Computational analysis of the interfacial bonding between feed-powder particles and the substrate in the cold-gas dynamic-spray process. Applied Surface Science, 219(3), 211-227. https://doi.org/10.1016/S01694332(03)00643-3

Grujicic, M., Zhao, C. ., DeRosset, W. ., \& Helfritch, D. (2004a). Adiabatic shear instability based mechanism for particles/substrate bonding in the cold-gas dynamic-spray process. Materials \& Design, 25(8), 681-688. https://doi.org/10.1016/j.matdes.2004.03.008

Grujicic, M., Zhao, C. L., DeRosset, W. S., \& Helfritch, D. (2004b). Adiabatic shear instability based mechanism for particles/substrate bonding in the cold-gas dynamic-spray process. Materials and Design, 25(8), 681-688. https://doi.org/10.1016/j.matdes.2004.03.008

Guetta, S., Berger, M. H., Borit, F., Guipont, V., Jeandin, M., Boustie, M., Ichikawa, Y., Sakaguchi, K., \& Ogawa, K. (2009). Influence of particle velocity on adhesion of cold-sprayed splats. In Journal of Thermal Spray Technology (Vol. 18, Issue 3, pp. 331-342). https://doi.org/10.1007/s11666-009-93270

Hassani-Gangaraj, M., Veysset, D., Champagne, V. K., Nelson, K. A., \& Schuh, C. A. (2018). Adiabatic shear instability is not necessary for adhesion in cold spray. Acta Materialia, 158, 430-439. https://doi.org/10.1016/j.actamat.2018.07.065

Kim, K., Watanabe, M., \& Kuroda, S. (2010). Bonding mechanisms of thermally softened metallic powder particles and substrates impacted at high velocity. Surface \& Coatings Technology, 204(14), 2175-2180. https://doi.org/10.1016/j.surfcoat.2009.12.001

King, P. C., Bae, G., Zahiri, S. H., Jahedi, M., \& Lee, C. (2010). An experimental and finite element study of cold spray copper impact onto two aluminum substrates. Journal of Thermal Spray Technology, 19(3), 620-634. https://doi.org/10.1007/s11666-009-9454-7

Li, W. Y., \& Gao, W. (2009). Some aspects on 3D numerical modeling of high velocity impact of particles in cold spraying by explicit finite element analysis. Applied Surface Science, 255(18), 78787892. https://doi.org/10.1016/j.apsusc.2009.04.135

Li, W. Y., Liao, H., Li, C. J., Li, G., Coddet, C., \& Wang, X. (2006). On high velocity impact of microsized metallic particles in cold spraying. Applied Surface Science, 253(5), 2852-2862. 
https://doi.org/10.1016/j.apsusc.2006.05.126

Lu, J., Zhang, H., Chen, Y., Zhao, X., Guo, F., \& Xiao, P. (2019). Effect of microstructure of a NiCoCrAlY coating fabricated by high-velocity air fuel on the isothermal oxidation. Corrosion Science, 159, 108126. https://doi.org/10.1016/j.corsci.2019.108126

Luzin, V., Spencer, K., \& Zhang, M. X. (2011). Residual stress and thermo-mechanical properties of cold spray metal coatings. Acta Materialia, 59(3), 1259-1270. https://doi.org/10.1016/j.actamat.2010.10.058

Manap, A., Ogawa, K., \& Okabe, T. (2011a). Numerical Analysis of Interfacial Bonding of Aluminum Powder Particle and Aluminum Substrate by Cold Spray Technique using the SPH Method. Proceedings of the JSME/ASME 2011 ICMP2011, Corvallis, Oregon,USA.

Manap, A., Okabe, T., \& Ogawa, K. (2011a). Computer simulation of cold sprayed deposition using smoothed particle hydrodynamics. Procedia Engineering, 10, 1145-1150. https://doi.org/10.1016/j.proeng.2011.04.190

Manap, Abreeza, Ogawa, K., \& Okabe, T. (2012). Numerical Analysis of Interfacial Bonding of Al-Si Particle and Mild Steel Substrate by Cold Spray Technique Using the SPH Method*. Journal of Solid Mechanics and Materials Engineering, 6(3). https://doi.org/10.1299/jmmp.6.241

Oyinbo, S. T., \& Jen, T.-C. (2019). A comparative review on cold gas dynamic spraying processes and technologies. Manufacturing Review, 11-13. https://doi.org/10.1051/mfreview/2019023

Oyinbo, S. T., \& Jen, T. C. (2020). Investigation of the process parameters and restitution coefficient of ductile materials during cold gas dynamic spray (CGDS) using finite element analysis. Additive Manufacturing, 31(November 2019), 100986. https://doi.org/10.1016/j.addma.2019.100986

Raoelison, R. N., Verdy, C., \& Liao, H. (2017). Cold gas dynamic spray additive manufacturing today: Deposit possibilities, technological solutions and viable applications. Materials \& Design, 133, 266287. https://doi.org/10.1016/j.matdes.2017.07.067

Richer, P., Zúñiga, A., Yandouzi, M., \& Jodoin, B. (2008). CoNiCrAlY microstructural changes induced during Cold Gas Dynamic Spraying. Surface and Coatings Technology, 203(3-4), 364-371. https://doi.org/10.1016/j.surfcoat.2008.09.014

Seraj, R. A., Abdollah-zadeh, A., Dosta, S., Assadi, H., \& Cano, I. G. (2019). Comparison of Stellite coatings on low carbon steel produced by CGS and HVOF spraying. Surface and Coatings Technology, 372, 299-311. https://doi.org/10.1016/j.surfcoat.2019.05.022

Suhonen, T., Varis, T., Dosta, S., Torrell, M., \& Guilemany, J. M. (2013). Residual stress development in cold sprayed $\mathrm{Al}, \mathrm{Cu}$ and $\mathrm{Ti}$ coatings. Acta Materialia, 61(17), 6329-6337. https://doi.org/10.1016/j.actamat.2013.06.033

Takana, H., Ogawa, K., Shoji, T., \& Nishiyama, H. (2008). Computational simulation of cold spray process assisted by electrostatic force. 185, 116-123. https://doi.org/10.1016/j.powtec.2007.10.005

Xie, J., Nélias, D., Ichikawa, Y., Walter-Le Berre, H., \& Ogawa, K. (2015). Simulation of the Cold Spray Particle Deposition Process. Journal of Tribology, 137(4), 041101. https://doi.org/10.1115/1.4030257

Yildirim, B., Muftu, S., \& A.Gouldstone. (2011). Modeling of high velocity impact of spherical particles. Wear, 270(9-10), 703-713.

Yin, S., Wang, X.-F., Li, W. Y., \& Jie, H.-E. (2011). Effect of substrate hardness on the deformation behavior of subsequently incident particles in cold spraying. Applied Surface Science, 257, 7560 7565. https://doi.org/10.1016/j.apsusc.2011.03.126

Yin, S., Wang, X., Suo, X., Liao, H., Guo, Z., Li, W., \& Coddet, C. (2013). Deposition behavior of thermally softened copper particles in cold spraying. Acta Materialia, 61(14), 5105-5118. https://doi.org/10.1016/J.ACTAMAT.2013.04.041

Zhang, Q., Li, C. J., Li, C. X., Yang, G. J., \& Lui, S. C. (2008). Study of oxidation behavior of nanostructured NiCrAlY bond coatings deposited by cold spraying. Surface and Coatings Technology, 202(14), 3378-3384. https://doi.org/10.1016/j.surfcoat.2007.12.028

Zhou, C. E., Liu, G. R., \& Lou, K. Y. (2007). Three-dimensional penetration simulation using smoothed particle hydrodynamics. International Journal of Computational Methods, 4(4), 671-691. https://doi.org/10.1142/S0219876207000972 
(C) 2021 by the authors; licensee Growing Science, Canada. This is an open access article distributed under the terms and conditions of the Creative Commons Attribution (CC-BY) license (http://creativecommons.org/licenses/by/4.0/). 